\title{
Raiva bovina na mesorregião nordeste do estado do Pará: uma abordagem agroambiental
}

A raiva é uma zoonose de curso geralmente fatal que acomete tanto animais quanto seres humanos, causada por um vírus Lyssavirus. A doença causa consideráveis perdas econômicas tanto ao agronegócio quanto ao setor público, além de sério problema de Saúde Pública. O principal transmissor da raiva para bovinos e humanos é o morcego hematófago Desmodus rotundus. A epidemiologia da raiva está diretamente relacionada à questão ambiental, a exemplo do desmatamento e da introdução de animais domésticos. 0 estudo foi na mesorregião Nordeste do Pará por ser proporcionalmente a mais desmatada e considerada área de principal foco da raiva bovina e foi conduzido de modo a analisar a evolução da ocorrência e distribuição espacial e temporal da raiva bovina por 13 anos, em dois períodos distintos, verificando-se a existência de tendência, difusão, ciclicidade e sazonalidade, além de relacionar os casos com desmatamento temporal da raiva bovina por 13 anos, em dois períodos distintos, verificando-se a existência de tendência, difusão, ciclicidade e sazonalidade, além de relacionar os casos com desmatamento análise estatística foram utilizados os programas Microsoft Excel ${ }^{\circledR} 2013$ e BioEstat 5.3. Os resultados demonstraram tendências diferentes de ocorrência da raiva nos períodos analisados, além de grande difusão da doença entre as microrregiões, exceto a microrregião Salgado que se apresentou como área silenciosa. As microrregiões Bragantina e Guamá se destacaram pelo elevado número de casos positivos e grande difusão entre seus municípios, respectivamente. A raiva apresentou maior correlação com o desmatamento do que com a atividade pecuária. A sazonalidade da doença não pode ser comprovada, porém é mais comum no período mais chuvoso. Sugere-se ciclicidade em áreas específicas da mesorregião Nordeste. $\mathrm{O}$ intenso desmatamento e a presença do vírus rábico nesta área demonstram quanto o desiquilíbrio ambiental tende a impactar negativamente na ocorrência de doenças como a raiva nesta área da Amazônia brasileira.

Palavras-chave: Vírus; Morcego; Pecuária; Desmatamento; Amazônia.

\section{Bovine rabies in the northeast mesoregion of Pará state: an agro- environmental approach}

\begin{abstract}
Rabies is a generally fatal course zoonosis which affects both animals and humans, caused by a Lyssavirus virus. The disease causes considerable economic losses to both agribusiness and the public sector, in addition to serious Public Health problem. The main cattle and human rabies transmitter is the Desmodus rotundus hematophagous bat. Rabies epidemiology is directly related to the environmental issue, such as deforestation and the introduction of domestic animals. The study was carried out in the Northeast mesoregion of Pará because it is proportionally the most deforested one and it is considered the main focus of bovine rabies and it was conducted in order to analyze the evolution of occurrence and spatial and temporal distribution of the most deforested one and it is considered the main focus of bovine rabies and it was conducted in order to analyze the evolution of occurrence and spatial and temporal distribution of
bovine rabies for 13 years, in two distinct periods, verifying the existence of tendency, cyclicality and seasonality, besides relating the cases with deforestation and cattle raising. Secondary data were obtained from official sources: Agricultural and Livestock Defense Agency (bovine rabies cases), IBGE (cattle raising) and INPE/PRODES (deforestation). For statistical analysis, Microsoft Excel ${ }^{\oplus} 2013$ and BioEstat 5.3 software were used. Results showed different tendencies in rabies occurrence in the analyzed periods, in addition to the disease wide spread among the microregions, except for the Salgado microregion, which presented itself as a silent area. The Bragantina and Guamá microregions stood out for the high number of positive cases and the wide spread among their municipalities, respectively. Rabies was more correlated with deforestation than cattle raising activity. The disease seasonality cannot be proven, however it was more common in the rainiest period. Cyclicality is suggested in Northeast mesoregion specific areas. The intense deforestation and the presence of rabies virus in this area demonstrate how environmental imbalance tends to negatively impact the occurrence of diseases such as rabies in this area of Brazilian Amazon.
\end{abstract}

Keywords: Virus; Bat; Cattle raising; Deforestation; Amazon.

Topic: Epidemiologia e Saúde Ambiental

Reviewed anonymously in the process of blind peer.

Lucila Pereira da Silva (iD)

Universidade do Estado do Pará, Brasil

http://lattes.cnpq.br/9588660640610043

http://orcid.org/0000-0003-0040-9482

lucilapsilva@yahoo.com.br

Altem Nascimento Pontes (iD)

Universidade do Estado do Pará, Brasil

https://lattes.cnpq.br/5993352890364998

http://orcid.org/0000-0002-9001-4603

altempontes@hotmail.com

Cléa Nazaré Carneiro Bichara

Universidade do Estado do Pará, Brasil

http://lattes.cnpq.br/2161704040280760

http://orcid.org/0000-0002-2995-0136

cleabichara@ig.com.br

d

DOI: 10.6008/CBPC2179-6858.2021.001.0012
Received: 02/01/2021

Approved: 25/01/2021
Referencing this:

SILVA, L. P.; PONTES, A. N.; BICHARA, C. N. C.. Raiva bovina na mesorregião nordeste do estado do Pará: uma abordagem agroambiental. Revista Ibero Americana de Ciências Ambientais, v.12, n.1, p.139-152, 2021. DOI: http://doi.org/10.6008/CBPC21796858.2021 .001 .0012 


\section{INTRODUÇÃO}

A raiva é uma das zoonoses de maior importância em Saúde Pública, é uma doença negligenciada (PUGA, 2015; WHO, 2018), causada por um vírus RNA do gênero Lyssavírus, família Rhabdoviridae e caracterizada por uma encefalite aguda, geralmente fatal (PÓVOAS et al., 2012; TEIXEIRA et al., 2015).

Na América Latina o morcego hematófago Desmodus rotundus é o principal reservatório e transmissor da raiva aos herbívoros domésticos, pois constituem sua fonte alimentar mais frequente (BÁRCENAS-REYES et al., 2015; DOGNANI et al., 2016). A alteração ambiental e a introdução de animais domésticos desequilibram a relação de comunidade ecológica de morcegos, favorecendo o aumento de populações de hematófagos (ALHO, 2012).

Embora a raiva urbana esteja em declínio no Brasil, o mesmo não acontece com a raiva dos herbívoros que pode ser caraterizada como endêmica e em graus diferenciados de acordo com a região do país (DOGNANI et al., 2016; PUGA, 2015; TEIXEIRA et al., 2015). No estado do Pará a vigilância da raiva animal envolve ações desenvolvidas pela Agência de Defesa Agropecuária - ADEPARÁ incluindo vigilância epidemiológica, vacinação dos herbívoros domésticos, controle populacional do morcego hematófago $D$. rotundus e educação em saúde.

A importância da verificação da raiva em herbívoros deve-se ao fato de serem considerados indicadores biológicos ou sentinelas quanto à circulação do vírus rábico no ambiente (SOUZA et al., 2014). No Brasil, a raiva causa grandes perdas econômicas no setor produtivo devido a morte de animais e no setor público devido aos custos dos programas de vigilância e controle (SOUSA, 2019).

A epidemiologia da raiva bovina está diretamente influenciada por fatores de ordem ambiental desencadeados pelos seres humanos. $O$ desmatamento é um dos fatores que mais interferem na ocorrência da raiva em bovinos contribuindo para a mudança da dinâmica da doença por reduzir o número de abrigos naturais e proporcionar a dispersão dos morcegos e assim a propagação da doença quando há colônias de morcegos infectados (ANDRADE et al., 2016).

De acordo com Villela et al. (2016), a mesorregião Nordeste foi proporcionalmente a mais desmatada (56,08\%) no estado do Pará, em razão da expansão agropecuária (COELHO et al., 2018). Seus municípios fazem parte da fronteira de ocupação antiga da Amazônia, marcados pelas seguintes atividades antrópicas: extração madeireira, agricultura de corte-queima e pecuária. Hoje possuem um sistema produtivo diversificado, com o domínio da agropecuária (CORDEIRO et al., 2017). As áreas desmatadas são ocupadas principalmente por pasto que se baseia em criação de bovinos de forma extensiva, seguida de vegetação secundária e de mosaico de ocupações (COELHO et al., 2018).

Considerando que a mesorregião Nordeste Paraense foi apontada como área de principal foco de circulação do vírus da raiva transmitido por morcegos hematófagos no Brasil (COSTA, 2011), inclusive com casos em humanos, e pelo fato da maioria dos casos de raiva bovina terem sido encontrados nesta área (ANDRADE et al., 2016), julgou-se importante avaliar a epidemiologia da raiva bovina e relaciona-la com pecuária bovina e desmatamento nesta localidade da Amazônia brasileira. 


\section{METODOLOGIA}

\section{Área de estudo}

A mesorregião Nordeste Paraense (Figura 1), segundo a divisão regional adotada pelo IBGE (2020a), é composta por cinco microrregiões, entre as quais: Guamá, Tomé-Açu, Cametá, Bragantina e Salgado, totalizando 49 municípios numa área territorial de $83.624 \mathrm{~km}^{2}$, correspondendo a 6,69\% da área total do estado. Contava com uma população em 2010, de 1.789.387 habitantes (IBGE, 2020b) e com um rebanho bovino em torno de 1.280 .000 cabeças em 2018 (IBGE, 2020c).

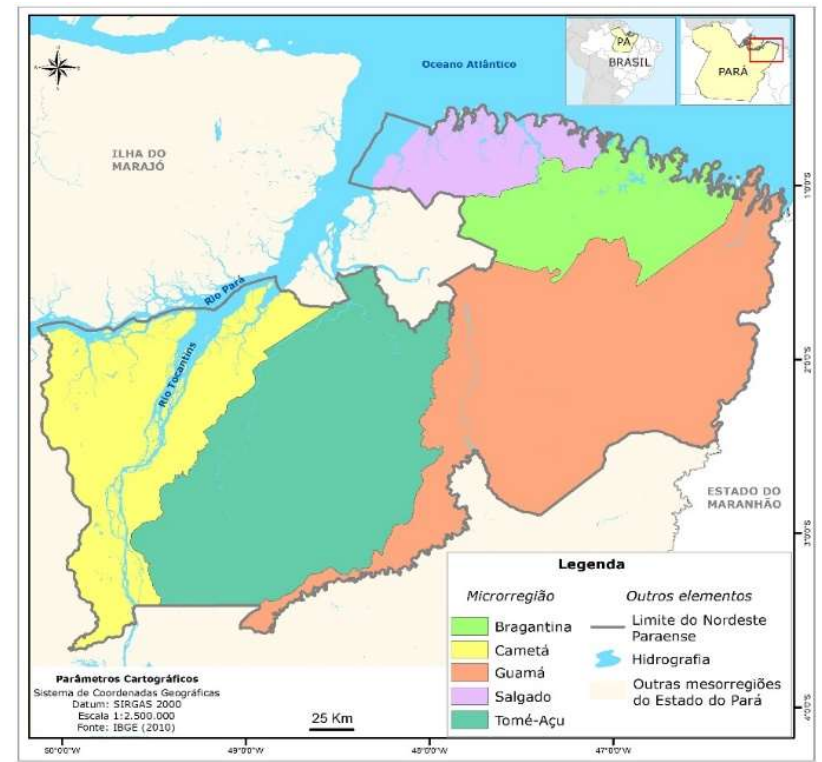

Figura 1: Localização geográfica da mesorregião Nordeste no estado do Pará.

Esta área amazônica é caracterizada pela ocorrência de temperaturas elevadas, acompanhadas de muita umidade, com chuvas abundantes e pluviosidade de 2.250 a $2.500 \mathrm{~mm}$ anuais, sendo a maior concentração no período de janeiro a junho (80\%). Historicamente vem sofrendo um processo de descaracterização devido ao desmatamento decorrente do modo de ocupação e de uso da terra, sendo considerada área sob antropismo com quase $25 \%$ de área desflorestada (CORDEIRO et al., 2017).

\section{Tipo de estudo e coleta de dados}

Trata-se de uma pesquisa epidemiológica, descritiva e retrospectiva, na qual foram analisados dados secundários da base de dados da Agência de Defesa Agropecuária do Estado do Pará - ADEPARÁ, referentes aos resultados do diagnóstico de raiva bovina de 49 municípios integrantes da mesorregião Nordeste Paraense no período de 2006 a 2018. As técnicas utilizadas para diagnóstico foram Imunofluorescência Direta e Prova Biológica, recomendadas pela Organização Mundial de Saúde (WHO, 2018).

Os dados referentes ao número de cabeças de bovino foram obtidos do Instituto Brasileiro de Geografia e Estatística (IBGE) e do desmatamento municipal do Instituto Nacional de Pesquisas Espaciais (INPE/PRODES). Para o PRODES, o corte raso é o processo final do desmatamento, indicando a supressão total da cobertura florestal. 


\section{Análise de dados}

Os resultados laboratoriais foram distribuídos por microrregião, mês e ano de ocorrência, sendo considerado como mês da ocorrência a data da coleta da amostra. Utilizou-se o software Microsoft Excel ${ }^{\circledR}$ 2013 para verificar: médias de rebanho bovino e desmatamento, percentuais de positividade e de municípios afetados, assim como a distribuição anual da raiva por microrregião. A taxa de incidência animal foi obtida pela seguinte fórmula: $\mathrm{n}$ o de bovinos positivos/total de bovinos nos municípios estudados x1.000.000 animais, conforme ano e área analisada.

Para uma melhor avaliação da tendência na ocorrência dos casos de raiva bovina e dos municípios afetados na mesorregião Nordeste, os resultados foram distribuídos em dois períodos distintos, de 2006 a 2012 e 2013 a 2018, sendo empregadas tendência linear e polinomial de grau 2, respectivamente. Na análise da significância foi empregada a regressão linear simples. Em situação da premissa de normalidade não ter sido atendida, os dados foram submetidos a transformação quadrática até se estabelecer o parâmetro de normalidade para então ser analisada a tendência através da regressão linear.

Verificou-se a normalidade dos dados através do teste de Shapiro-Wilk para então calcular a correlação linear de Pearson entre as seguintes variáveis: número de amostras analisadas e número de amostras positivas; número de casos de raiva e o número de municípios afetados. A relação entre raiva, pecuária bovina e desmatamento na mesorregião foi obtida pela média obtida das microrregiões.

Na comparação da diferença entre casos de raiva nas duas estações do ano utilizou-se o teste de Mann Whitney para avaliação da existência de sazonalidade da raiva bovina na mesorregião. A classificação entre estação mais chuvosa (janeiro a agosto) e menos chuvosa (setembro a dezembro) obedecerá ao proposto por Moraes et al. (2005). Nas análises de correlação linear e Mann Whitney foi utilizado o programa BioEstat 5.3, à nível de significância de 5\% $(0,05)$ e intervalo com confiabilidade de 95\% (AYRES et al., 2007).

\section{RESULTADOS}

Foram analisadas 222 amostras de bovinos suspeitas de síndrome neurológica compatíveis com a raiva, destas 83 resultaram positivo (37,38\%). As microrregiões Bragantina e Guamá foram as que mais enviaram amostras suspeitas e onde foram concentrados o maior número de casos ( $n=70)$. Na distribuição geográfica, a raiva bovina ocorreu em 20 dos 49 municípios que integram a mesorregião Nordeste Paraense, correspondendo a 40,81\%. A microrregião Guamá apresentou maior percentual de municípios afetados, aproximadamente $70 \%$, seguida da microrregião Tomé-Açu (60\%) e não houve registro de raiva bovina na região Salgado (Tabela 1 ).

Na avaliação do total de municípios da mesorregião Nordeste afetados pela doença observou-se que no 1 o período houve tendência significativa de redução de municípios afetados $(p=0,0009$; coeficiente angular de regressão " $b$ " = - 0,77 e IC 95\%: - 1,053 a-0,487). Já no 2o período houve tendência de aumento, mas não significativo ( $p=0,0698$; coeficiente angular de regressão " $b$ " = 0,5263 e IC 95\%= - 0,068 a 1,121) Figura 2. 
Tabela 1: Difusão da raiva bovina, amostras examinadas, casos positivos e taxa de positividade entre as microrregiões da mesorregião Nordeste Paraense, no período de 2006 a 2018

\begin{tabular}{|c|c|c|c|c|c|c|}
\hline Microrregião & $\begin{array}{l}\text { Total de } \\
\text { Municípios }\end{array}$ & $\begin{array}{l}\text { Municípios } \\
\text { afetados }\end{array}$ & $\begin{array}{l}\text { Difusão da raiva entre } \\
\text { os municípios }\end{array}$ & $\begin{array}{l}\text { Amostras } \\
\text { analisadas }\end{array}$ & $\begin{array}{l}\text { Casos } \\
\text { positivos }\end{array}$ & $\begin{array}{l}\text { Taxa } \\
\text { positividade (\%) }\end{array}$ \\
\hline Bragantina & 13 & 6 & $46,15 \%$ & 88 & 45 & 51,13 \\
\hline Guamá & 13 & 9 & $69,23 \%$ & 90 & 25 & 27,77 \\
\hline Cametá & 7 & 2 & $28,57 \%$ & 15 & 4 & 26,66 \\
\hline Tomé-Açu & 5 & 3 & $60 \%$ & 22 & 9 & 40,90 \\
\hline Salgado & 11 & 0 & $0 \%$ & 7 & 0 & 0,0 \\
\hline Total & 49 & 20 & $40,81 \%$ & 222 & 83 & 37,38 \\
\hline
\end{tabular}
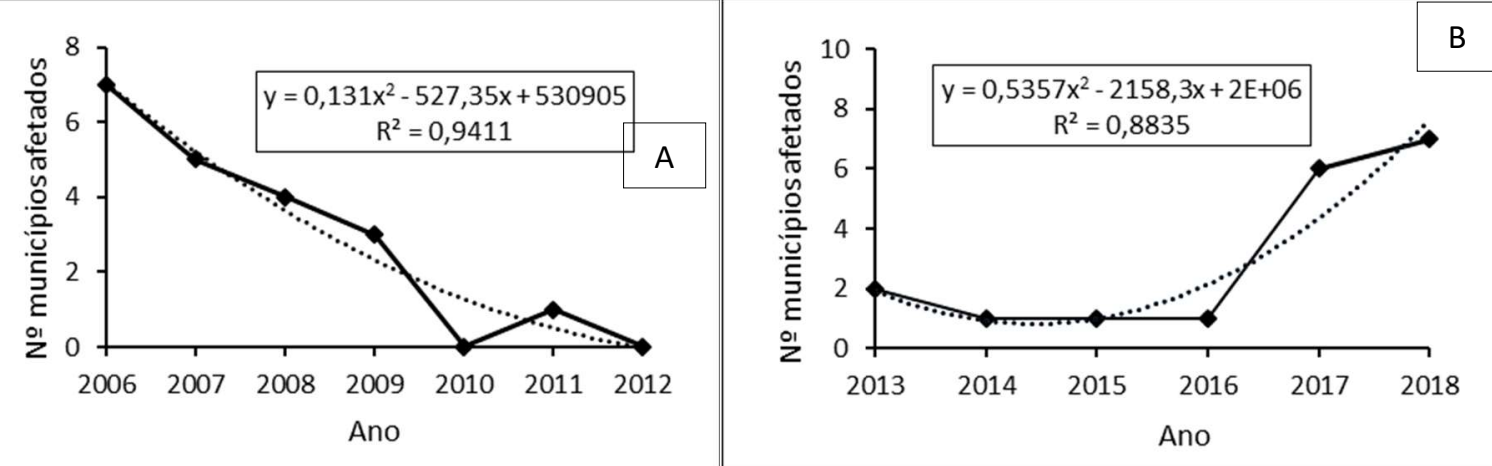

Figura 2: Tendência de ocorrência da raiva bovina nos municípios da mesorregião Nordeste Paraense, nos períodos de 2006 a 2012 (A) e 2013 a 2018 (B).

A ocorrência de casos de raiva bovina na mesorregião Nordeste em dois períodos distintos: de 2006 a 2012 e 2013 a 2018 apresentou tendência significativa de redução ( $p=0,0154$; coeficiente angular de regressão ' $b$ ' = - 0,6651 e IC 95\%: - 0,191 a -1,139) e de aumento significativo de 2,4 casos/ano ( $p=0,0376$; coeficiente angular de regressão ' $b$ '= 0,0321 e IC 95\%: 0,003 a 0,061), respectivamente (Figura 3).

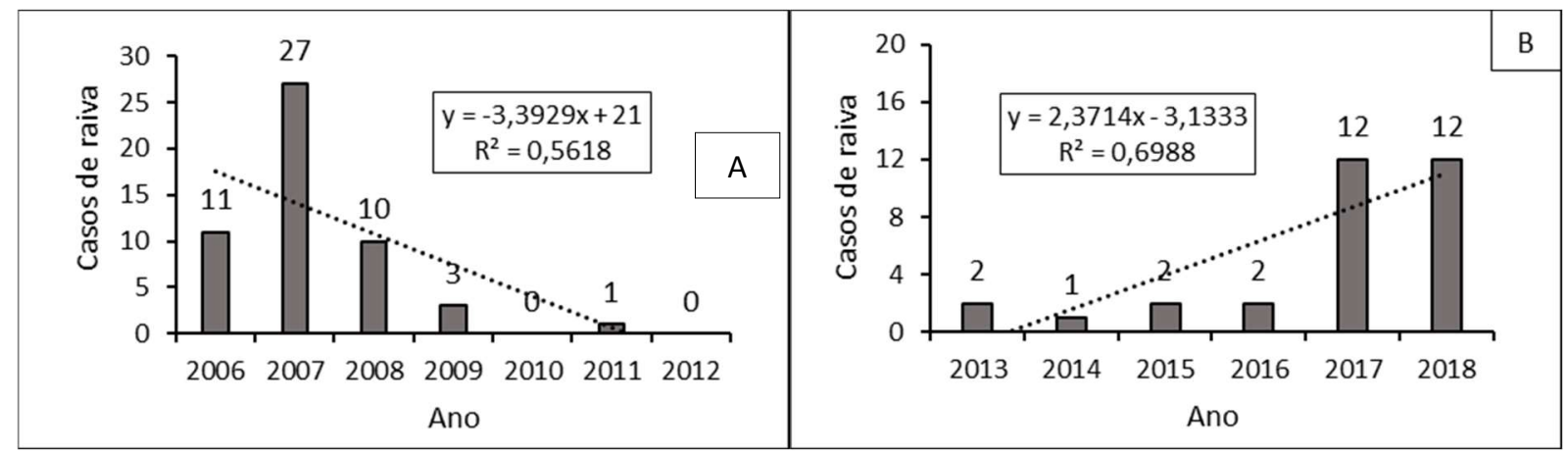

Figura 3: Tendência da raiva bovina na mesorregião Nordeste Paraense, nos períodos de 2006 a 2012 (A) e 2013 a 2018 (B).

A microrregião Bragantina apresentou maior percentual de positividade (54\%) em relação ao número total de amostras positivas da mesorregião ( $n=83)$, seguida da microrregião Guamá (30\%) - Figura 4.

Foram verificados picos de ocorrência da doença em 2007 e 2017 nas seguintes áreas: Bragantina, Guamá e Tomé-Açu. Notadamente houve ausência de casos em todas as microrregiões em 2010 e 2012 (Figura 5).

A taxa de incidência animal $\left(\times 10^{6}\right)$ por microrregião foi bastante variada. No entanto, as maiores taxas de incidência ocorreram em 2007 nas microrregiões: Bragantina (9,24 por 1.000.000 animais) e Guamá (9,22 por 1.000.000 animais) e em 2017 também na Guamá (8,69 por 1.000 .000 animais) (Figura 6). 


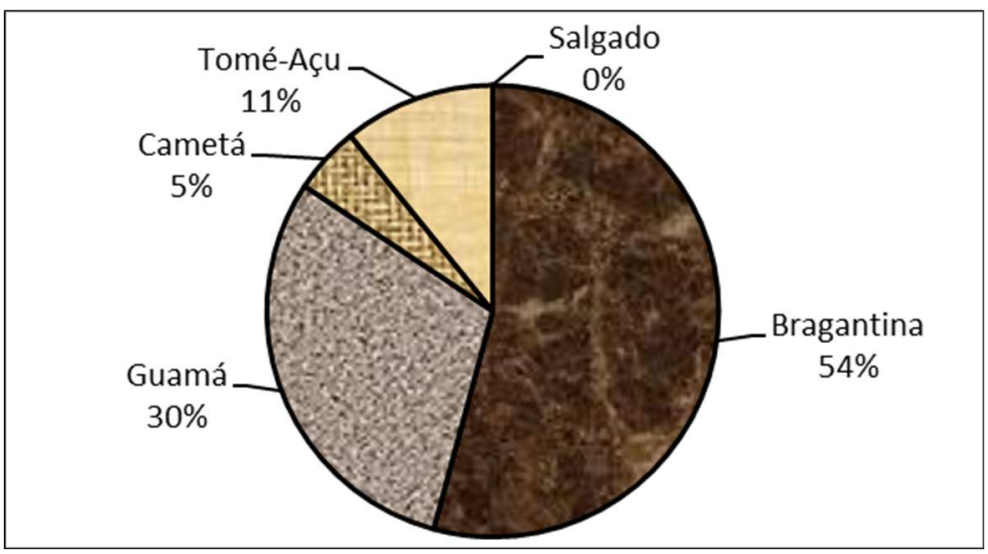

Figura 4: Distribuição percentual da raiva bovina por microrregião da mesorregião Nordeste Paraense, no período de 2006 a 2018.

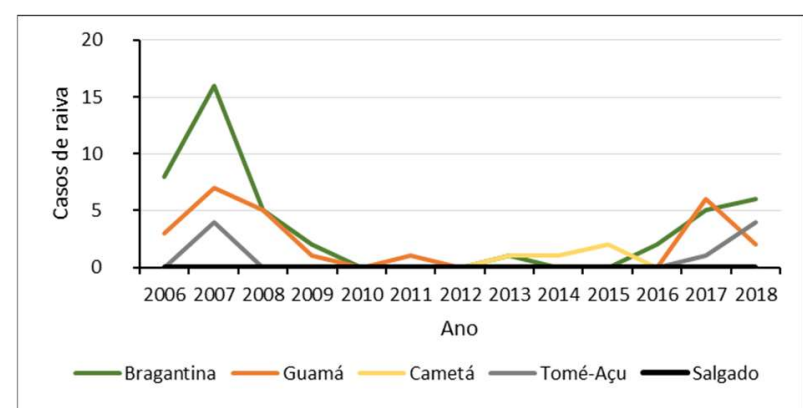

Figura 5: Distribuição anual da raiva bovina por microrregião da mesorregião Nordeste Paraense, no período de 2006 a 2018.

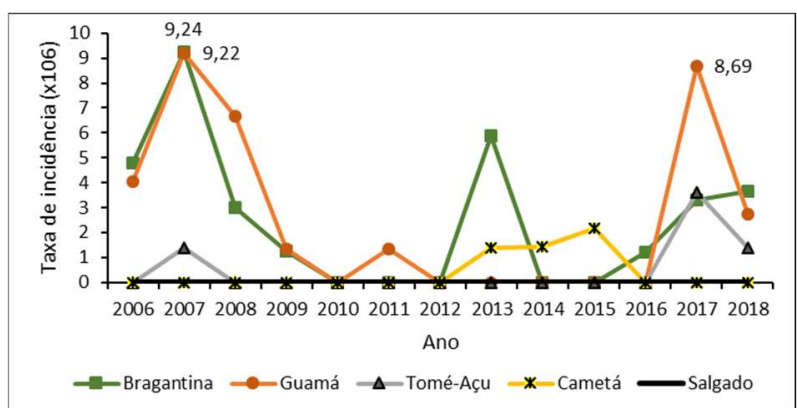

Figura 6: Comparativo da taxa de incidência $\left(10^{6}\right)$ da raiva bovina entre as microrregiões da mesorregião Nordeste Paraense, no período de 2006 a 2018.

Devido ao fato de haver diferença na extensão territorial $\left(\mathrm{km}^{2}\right)$ entre as microrregiões, os dados do desmatamento foram apresentados em termos percentuais em relação à área total. A evolução do rebanho bovino (IBGE, 2020c) e do desmatamento (INPE/PRODES, 2020) por microrregião encontram-se distribuídos na tabela 2, no qual se verifica que microrregião Guamá se destacou pelo maior rebanho bovino e a Bragantina por possuir maior percentual desmatado em relação a área total.

Tabela 2: Evolução do rebanho bovino e do desmatamento acumulado (\%) entre as microrregiões da mesorregião Nordeste Paraense, no período de 2006 a 2018.

\begin{tabular}{l|l|l|l|l|l|l|l|l|l|l}
\hline \multirow{2}{*}{ Ano } & \multicolumn{3}{l}{ Bragantina } & \multicolumn{2}{l|}{ Guamá } & \multicolumn{2}{l|}{ Cametá } & \multicolumn{2}{l}{ Tomé- Açu } & \multicolumn{2}{l}{ Salgado } \\
\cline { 2 - 12 } & B & D & B & D & B & D & B & D & B & D \\
\hline 2006 & 167.190 & 74.70 & 741.648 & 68.35 & 65.084 & 29.55 & 347.732 & 47.61 & 26.855 & 36.29 \\
\hline 2007 & 173.081 & 74.96 & 759.056 & 68.75 & 73.048 & 29.76 & 284.745 & 48.50 & 31.686 & 36.55 \\
\hline 2008 & 165.342 & 75.36 & 749.908 & 69.36 & 76.665 & 29.93 & 360.294 & 49.65 & 33.242 & 36.97 \\
\hline 2009 & 156.966 & 75.52 & 744.996 & 70.30 & 78.945 & 30.14 & 297.790 & 50.12 & 21.525 & 37.11 \\
\hline 2010 & 144.110 & 75.62 & 725.442 & 70.82 & 81.798 & 30.86 & 272.481 & 51.10 & 17.098 & 37.32 \\
\hline 2011 & 149.830 & 75.69 & 726.843 & 71.22 & 84.746 & 30.98 & 255.407 & 51.46 & 21.598 & 37.40 \\
\hline 2012 & 159.598 & 75.70 & 751.043 & 71.29 & 69.575 & 31.07 & 261.288 & 51.70 & 17.769 & 37.44 \\
\hline 2013 & 169.346 & 75.75 & 756.472 & 71.43 & 72.263 & 31.16 & 164.238 & 52.13 & 23.836 & 37.62 \\
\hline 2014 & 167.720 & 75.77 & 791.571 & 71.57 & 70.329 & 31.17 & 248.507 & 52.33 & 23.635 & 37.66 \\
\hline 2015 & 166.420 & 75.84 & 784.533 & 71.72 & 92.378 & 31.21 & 271.777 & 52.53 & 22.760 & 37.82 \\
\hline 2016 & 163.867 & 75.87 & 771.819 & 71.87 & 70.287 & 31.28 & 279.569 & 52.77 & 25.204 & 37.91 \\
\hline 2017 & 151.814 & 75.94 & 689.898 & 72.12 & 77.674 & 31.38 & 275.573 & 53.09 & 20.909 & 38.01 \\
\hline 2018 & 163.750 & 75.97 & 734.287 & 72.29 & 61.044 & 31.47 & 290.844 & 53.81 & 26.005 & 38.12 \\
\hline Média & 161.462 & 75.64 & 748.270 & 70.85 & 74.910 & 30.77 & 277.711 & 51.29 & 24.009 & 37.40 \\
\hline
\end{tabular}

$\mathrm{B}=\mathrm{N}$ o de cabeças bovino/ $\mathrm{D}=$ Desmatamento em percentual.

Os resultados da relação entre amostras suspeitas analisadas e amostras positivas na mesorregião indicaram forte correlação significativa $\left(r=0,9157 ; R^{2}=0,8385 ; p=0,0029\right)$ e entre número de casos de raiva 
e o número de municípios afetados na mesorregião também indicaram forte correlação significativa ( $r=$ 0,$\left.9168 ; R^{2}=0,8405 ; p<0.0001\right)$.

Os resultados da relação entre casos de raiva e desmatamento da mesorregião Nordeste apresentaram forte correlação significativa $\left(r=0,9164 ; R^{2}=0,8398 ; p=0,0286\right)$, já entre desmatamento e pecuária $\left(r=0,6181, R^{2}=0,382, p=0,2664\right)$ e entre pecuária bovina e casos de raiva $\left(r=0,3438, R^{2}=0,1182\right.$, $p=0,571$ ) apresentaram baixa correlação, estatisticamente não significativa.

No que se refere à ocorrência mensal na mesorregião observou-se que a doença ocorreu em todos os meses, com maior concentração ( $n=62$ ) na estação mais chuvosa (janeiro a agosto). O perfil da ocorrência na estação mais chuvosa apresentou certa regularidade em relação ao número de casos positivos e com pico no mês de agosto. Em relação à estação menos chuvosa está apresentou pico de ocorrência no mês de novembro (Figura 7).

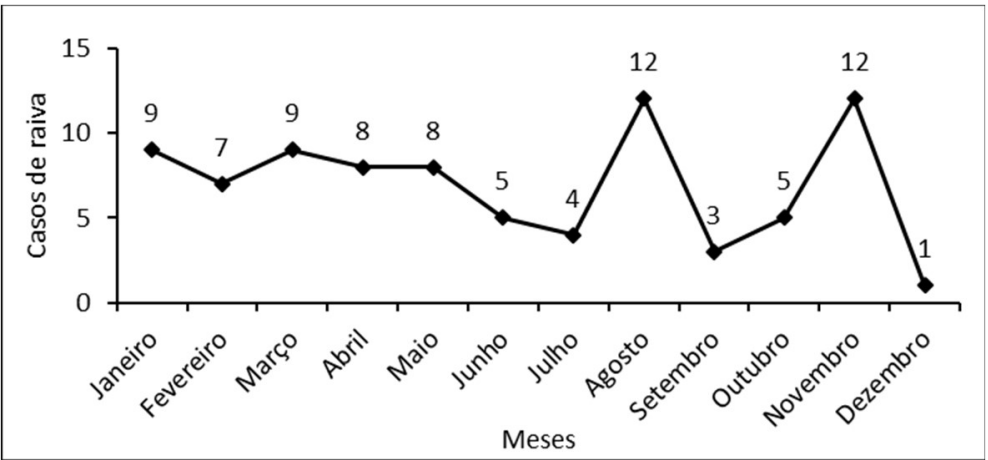

Figura 7: Distribuição mensal dos casos de raiva bovina na mesorregião Nordeste Paraense, no período de 2006 a 2018.

Em quase todas as microrregiões foi observada predominância de casos na estação mais chuvosa, a única exceção foi a Tomé-Açu (Figura 8). Muito embora a maioria dos casos ( $n=62$ ) tenha ocorrido na estação mais chuvosa, não houve diferença estatisticamente significativa entre casos de raiva na estação mais chuvosa e na menos chuvosa ( $p$-valor=0,5637).

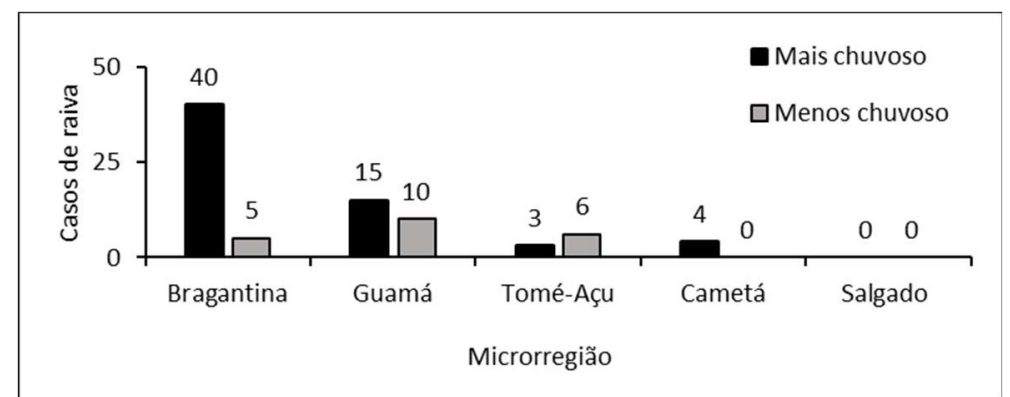

Figura 8: Distribuição dos casos de raiva bovina por microrregião da mesorregião Nordeste Paraense, no período de 2006 a 2018, segundo a estação do ano.

\section{DISCUSSÃO}

A taxa de positividade geral em bovinos encontrada de 37,38\% na mesorregião Nordeste Paraense, embora seja um estudo regionalizado, mostra-se relevante quando comparada com outras pesquisas nacionais que verificaram taxas de positividade diferentes deste trabalho. Em São Paulo (QUEIROZ et al., 2009), no Paraná (DOGNANI et al., 2016), em Goiás (DIOGO FILHO et al., 2017), no Pará (RODRIGUES et al., 
2018), as taxas de positividade em bovinos foram respectivamente, $13 \%, 30,6 \%, 30,77 \%, 34,71 \%$. Em Pernambuco a taxa de positividade foi de $51,6 \%$ em bovídeos (SOUSA, 2019). Já no município de Bragança/PA (microrregião Bragantina) foi verificado aproximadamente $73 \%$ de positividade em bovídeos (SILVA et al., 2020).

A taxa de positividade variou entre as microrregiões, sendo que a Bragantina apresentou maior percentual de positividade $(51,13 \%)$ em relação ao número total de amostras analisadas por microrregião, seguida da Tomé-Açu (40,90\%), muito embora esta tenha enviado para análise um menor quantitativo de amostras ( $n=22)$ em relação à microrregião Guamá $(n=90)$. As microrregiões Guamá e Cametá apresentaram valores aproximados de positividade em relação ao total de amostras analisadas.

A tendência da ocorrência da raiva, assim como do número de municípios afetados na mesorregião como um todo, parece indicar que as ações de controle foram eficientes apenas no primeiro período, talvez em resposta às ações de controle de morcegos hematófagos, educação sanitária e vacinação dos animais realizada pelo órgão de defesa animal do estado. Entretanto, não se pode descartar a possibilidade de esta diminuição estar relacionada ao não envio de material para laboratório por parte dos veterinários, o que já havia sido relatado por Teixeira et al. (2015). Espera-se aumento no número de casos de raiva bovina na mesorregião, pois foi observada tendência de aumento no segundo período analisado $(p<0,05)$.

Analisando cada microrregião nos 13 nos de estudo verificou-se que a raiva está mais difundida na Guamá (69\%) e Tomé-Açu (60\%) por possuírem maior percentual de municípios com registro da doença. Essa expansão geográfica pode ser verificada na microrregião Cametá que passou a registrar casos de raiva somente a partir de 2013, provavelmente devido a migração de quirópteros infectados oriundos da ToméAçu, pois a ampla distribuição geográfica do $D$. rotundus e a livre circulação do vírus entre os morcegos são dois dos fatores que mais contribuem para a persistência da doença na região amazônica brasileira (ANDRADE et al., 2016).

Cabe salientar que nenhum método de controle eliminou a circulação do vírus da raiva, mesmo naquelas áreas onde o controle de morcegos hematófagos é realizado regularmente (BLACKWOOD et al., 2013) e que a maioria das exposições ao vírus rábico entre os morcegos hematófagos não são letais e os imunizaria, e isto facilitaria a persistência viral, o que garantiria a reinfecção das colônias de morcegos (PEREIRA et al., 2011). Tais considerações poderiam explicar o aumento da tendência de casos e do número de municípios afetados na mesorregião no 2 período do estudo.

A região do Salgado apresentou-se como área silenciosa e alguns fatores podem ser considerados dentre os quais o baixo efetivo rebanho e o baixo percentual de área desmatada, esta situação provavelmente proporcionaria a manutenção do nicho ecológico dos quirópteros, o que evitaria maior deslocamento e ataque de morcegos hematófagos nos bovinos. Também há que se considerar a possibilidade de subnotificação que é uma condição comum em todo o território nacional (DOGNANI et al., 2016) e o estado do Pará não pode ser uma exceção. Neste aspecto, acredita-se que para caso confirmado possam existir cerca de 10 outros que não sejam diagnosticados (BÁRCENAS-REYES et al., 2015; SOUZA et al., 2014). No que se refere à Portaria Estadual № 3.592/2018 (PARÁ, 2018) que estabeleceu obrigatoriedade 
de vacinação antirrábica animal em alguns municípios paraenses entre eles alguns pertencentes às microrregiões Bragantina e Guamá, motivadas obviamente pela importância epidemiológica dessas duas áreas, observou-se que certas áreas consideradas neste trabalho como "silenciosas" foram abrangidas para vacinação compulsória, talvez como medida preventiva e que a região Tomé-Açu, embora tenha apresentado grande difusão da doença não foi incluída nesta medida.

Outra questão relevante é o fato de que aproximadamente $63 \%$ das amostras analisadas resultaram negativas para raiva. Teixeira et al. (2015) verificaram $86,84 \%$ de negatividade nas amostras de bovinos suspeitas de raiva, já Diogo Filho et al. (2017) verificou percentual 70\% de negatividade, sendo então considerado como uma situação que necessite de aprimoramento no diagnóstico clínico-epidemiológico de outras doenças que também apresentam sintomatologia nervosa. De acordo com os dados disponibilizados pela ADEPARÁ não foi possível afirmar se as amostras negativas foram ou não submetidas ao diagnóstico diferencial.

A forte correlação positiva entre número de amostras enviadas para diagnóstico e número de casos positivos na mesorregião indica que o aumento do número de amostras analisadas representaria também um aumento de casos confirmados da doença, vindo a corroborar com Rodenbush et al. (2016) que afirmaram que quanto maior o número de amostras analisadas maior será o número de casos confirmados, o que implicaria em um sistema de controle da doença mais sensível.

A forte correlação positiva entre o número de casos positivos e o número de municípios afetados na mesorregião indica que o aumento no número de casos de raiva é acompanhado de aumento de municípios afetados, mostrando que a ocorrência da doença parece não estar restrita a uma região, mas sim expansão geográfica da doença, principalmente nas microrregiões Guamá e Tomé-Açu, conforme já relatado. Estudo semelhante considerou como de grande difusão quando foram afetados $47,6 \%$ do total de municípios no Paraná (DOGNANI et al., 2016), mas Silva et al. (2017), ao contrário do presente estudo, não observaram correlação entre estas variáveis no estado do Mato Grosso.

A forte correlação encontrada entre raiva bovina e desmatamento indica que o desmatamento nesta localidade da Amazônia ao longo dos anos tem contribuído sobremaneira para a ocorrência da doença nestes animais. Hoje é comum se encontrar na mesorregião Nordeste do Pará, paisagens com erosões, rios e igarapés assoreados, fauna e flora em extinção, além de alterações climáticas (CORDEIRO et al., 2017). Esta condição favorável já havia sido relatada por Andrade et al. (2016) ao considerar o lado leste paraense como de alto risco para bovinos justamente pelas grandes áreas desmatadas, assim como grandes rebanhos e numerosas rodovias.

Considerando que os casos de raiva e pecuária bovina não se relacionaram estatisticamente, isto divergiu um pouco do conceito comum de que os casos de raiva estão associados ao aumento da produção bovina, devido ao gado ser considerado uma fonte farta de alimentação para o morcego e uma presa de fácil acesso (FERNANDES et al., 2013). Em Minas Gerais a principal variável correlacionada com a raiva bovina foi a lavoura permanente, além de pastagens naturais e plantadas e efetivo bovino e menor associação com matas naturais (SILVA et al., 2001). Igualmente em Goiás a única variável que apresentou correlação com a 
raiva foi a lavoura permanente, indicando que possivelmente outros fatores, como a presença de morcegos hematófagos, abrigos artificiais e os distúrbios ambientais possam ter influenciado mais diretamente na distribuição da doença (DIOGO FILHO et al., 2017).

Cabe destacar que o efetivo rebanho por si só, não é fator diretamente ligado ao número de casos de raiva (DOGNANI et al., 2016) e que no Nordeste Paraense o rebanho bovino teve consideráveis oscilações ao longo da série histórica. Nesse aspecto, pondera-se que a produção de carne bovina apresenta característica complexa e dinâmica na qual choques de oferta e de demanda influenciam a evolução da produção como um todo ao longo de um período de tempo, os chamados ciclos da carne (IPEA, 2019).

No presente estudo observou-se correlação moderada $(r=0,6181)$ entre desmatamento e pecuária bovina, mas não significativa, o que se considera um fenômeno interessante, pois o desmatamento na Amazônia brasileira tem sido causado pela conversão de floresta, principalmente para pecuária, agricultura de corte e queima ou associada à exploração madeireira, sendo que destes a expansão da pecuária bovina é a mais importante (RIVERO et al., 2009).

Estudo semelhante na mesorregião Sudeste paraense apresentou forte correlação $(r=0,97)$ entre desmatamento e rebanho bovino, mas sem explicitar a significância do teste estatístico empregado (NEVES et al., 2014), assim como no município de Bragança/PA (microrregião Bragantina) verificou-se forte correlação significativa ( $r=0,7418 ; p=0,0037)$ entre desmatamento e pecuária bovídea (SILVA et al., 2020).

No caso da mesorregião Nordeste Paraense é provável que outras condicionantes, além da questão pecuária, estejam interferindo na dinâmica do desmatamento, assim como explicitado por Rivero et al. (2009) quando se refere as causas indiretas ou subjacentes para o desmatamento que estão associadas com o crescimento dos mercados para os produtos que produzem a mudança de uso do solo, com a urbanização e com o crescimento populacional, com fatores estruturais, culturais e, finalmente, com políticas governamentais. Muito embora tenha se verificado baixo incremento anual no desmatamento das microrregiões, sabe-se que ocorrem oscilações do desmatamento, ao longo do tempo, de caráter cíclico que acompanham o ciclo econômico mundial, principalmente em razão dos preços e da demanda internacional por madeira, carnes, grãos e minérios (VILLELA et al., 2016).

A existência de picos de ocorrência da doença nas regiões Bragantina e Guamá é uma observação importante, pois corrobora que a raiva é uma doença cíclica (PÓVOAS et al., 2012). Esta característica de ciclicidade da raiva pode ser em decorrência do maior número de morcegos infectados nos picos da doença nos herbívoros, os quais morrem em certa quantidade e posteriormente ocorre período de declínio, para repovoamento e reinfecção das colônias de morcegos, pois o crescimento das mesmas é lento (PEREIRA et al., 2011; RIBEIRO et al., 2018).

Alguns autores asseguram que a raiva ocorra de 3 a 7 anos (PEREIRA et al., 2011; PÓVOAS et al., 2012) ou até 18 anos (DOGNANI et al., 2016). No município de Bragança/PA foi sugerida a existência tanto de ciclicidade quanto de sazonalidade da raiva em herbívoros (SILVA et al., 2020). Já outros não confirmaram a existência de ciclicidade da doença (RIBEIRO et al., 2018; RODENBUSH et al., 2016; SOUSA, 2019).

Quanto à sazonalidade observou-se que a maioria dos casos positivos ocorreu na estação mais 
chuvosa tanto analisando a mesorregião como um todo quanto as cinco microrregiões separadamente, à exceção foi a região Tomé-Açu, que por razões ainda desconhecidas apresentou comportamento diferente das demais áreas. Devido ao fato da associação da ocorrência de casos e das estações do ano ter comprovada não significativa não se pode confirmar a influência de sazonalidade na incidência da raiva bovina, mas foi verificado picos de ocorrência da doença nos meses de agosto (final do mais chuvoso) e novembro (menos chuvoso).

A maioria dos estudos na literatura brasileira sobre sazonalidade da raiva analisa as quatro estações do ano (outono, inverno, primavera e verão) e neste trabalho considerou-se duas: mais chuvosa e a menos chuvosa, por serem as definidas para a região amazônica, sendo escassos os trabalhos abordando está temática, porém Costa (2001) verificou maior soropositividade em quirópteros no período mais chuvoso na região Nordeste do Pará, assim como Silva et al. (2020) verificaram maior ocorrência da doença em bovídeos no período mais chuvoso, corroborando com resultados encontrados neste estudo.

Pereira et al. (2011) citam que no Mato Grosso do Sul a raiva tem tendência a ser sazonal, com maior ocorrência no outono, cuja sazonalidade provavelmente ocorreria devido ao ciclo biológico do morcego, cujo acasalamento ocorreria na primavera, no qual ocorreria aumento da transmissão do vírus entre as colônias com pico de surtos no outono em função do período de incubação da doença nos morcegos e nos bovinos agredidos. Mas, de maneira geral, a raiva pode ocorrer em qualquer época do ano. Não obstante, Diogo Filho et al. (2017), Dognani et al. (2016) e Sousa (2019) não evidenciaram a existência de sazonalidade da raiva em Goiás, Paraná e Pernambuco, respectivamente.

No que se refere à variabilidade dos valores das taxas de incidência animal entre as microrregiões deve ser considerado que a variabilidade regional de ocorrência da raiva dentro de um mesmo estado é comum (DOGNANI et al., 2016). Notadamente, as microrregiões Bragantina e Guamá apresentaram as maiores taxas de incidência, muito embora o quantitativo efetivo bovino e casos de raiva tenham sido bem diferentes entre as mesmas.

Ressalta-se que as cinco microrregiões estudadas possuem condições ambientais distintas, além de estarem sujeitas à ocorrência dos fenômenos El Niño e La Niña, caracterizados em seus efeitos na estação chuvosa com índice pluviométrico abaixo da normalidade e um acréscimo na quantidade de chuva, respectivamente (ANDRADE et al., 2017; GOMES et al., 2019). Isto deve ser considerado em relação a variabilidade na ocorrência da raiva nas microrregiões estudadas, pois a variabilidade do número de casos de raiva também ocorre pelas condições climáticas que afetam no ciclo de vida do morcego vampiro (BÁRCENAS-REYES et al., 2015; BLACKWOOD et al., 2013).

\section{CONCLUSÕES}

O vírus rábico circula na maioria das microrregiões do Nordeste Paraense. Destacando-se as microrregiões Bragantina e a Guamá, ambas representando grande importância epidemiológica para a raiva, seja pelo elevado número de casos positivos, seja pela grande difusão entre os municípios, respectivamente, e ambas pela alta incidência da doença entre bovinos. Notadamente, a microrregião Cametá passou a 
registrar casos a partir de 2013, provavelmente devido a migração de quirópteros infectados oriundos da microrregião Tomé-Açu.

A raiva bovina no Nordeste Paraense apresentou maior relação com o desmatamento do que com a pecuária, evidenciando que o desiquilíbrio ambiental na área tende a impactar negativamente na ecologia dos morcegos, inclusive com perda de habitat, favorecendo a sua dispersão para outras áreas e assim contribuindo para a ocorrência da raiva, além de outras zoonoses de importância em Saúde Pública. Embora seja quase impossível não associar desmatamento à pecuária, sugere-se que além da questão pecuária outras variáveis, extrínsecas e/ou intrínsecas, possam estar influenciando mais diretamente na dinâmica da raiva bovina.

Apesar de a região do Salgado ter se apresentado como área silenciosa, não se pode afirmar que o vírus da raiva não circule nesta área, considerando ser limítrofe à região Bragantina que apresentou maior número de casos confirmados e grande difusão do vírus entre seus municípios de abrangência. Neste caso, não pode ser descartada a possibilidade de existência de subnotificação.

Não foi possível a confirmação da sazonalidade da raiva no Nordeste Paraense, apesar da doença em bovinos ser mais comum na estação mais chuvosa. Quanto à ciclicidade da doença sugere-se que ocorra em áreas específicas da mesorregião.

Devido a ocorrência de diferentes tendências da raiva bovina no Nordeste Paraense ao longo da série histórica, recomenda-se que as ações de controle da raiva em herbívoros sejam mais uniformes e eficientes, principalmente por considerar a existência de áreas silenciosas que podem esconder a real situação epidemiológica de uma área. Espera-se que os resultados encontrados sirvam de base para tomada de decisões na defesa sanitária animal, principalmente quanto à determinação de áreas prioritárias para vacinação antirrábica, além de reforçar a importância do acompanhamento de eventos sentinela que podem alertar' sobre a circulação do vírus rábico e assim possível prevenção da infecção em humanos, fatos já ocorridos na Amazônia brasileira.

\section{REFERÊNCIAS}

ALHO, C. J. R.. Importância da biodiversidade para a saúde humana: uma perspectiva ecológica. Estudos Avançados, São Paulo, v.26, n.74, 2012. DOI:

http://dx.doi.org/10.1590/S0103-40142012000100011

ANDRADE, F. A. G.; GOMES, M. N.; UIEDA, W.; BEGOT, A. L.; RAMOS, O. S.; FERNANDES, M. E. B.. Geographical analysis for detecting high-risk areas for bovine/human rabies transmitted by the common hematophagous bat in the Amazon region, Brazil. PLOS ONE, San Francisco, v.11, n.7, p.1-15, 2016. DOI:

https://doi.org/10.1371/journal.pone.0157332

ANDRADE, V. M. S.; CORDEIRO, I. M. C. C.; SCHWARTZ, G.; RANGEL-VASCONCELOS, L. G. T.; OLIVEIRA, F. A.. Considerações Sobre Clima e Aspectos Climáticos e Edáficos da Mesorregião Nordeste Paraense. In: CORDEIRO, I. M. C. C.; RANGELVASCONCELOS, L. G. T.; SCHWARTZ, G.; OLIVEIRA, F. A.. Nordeste Paraense: panorama geral e uso sustentável das florestas secundárias. Belém: EDUFRA, 2017. p.59-96.
AYRES, M.; AYRES JUNIOR, M.; AYRES, D. L.; SANTOS, A. A. S.. Bioestat 5.3 Aplicações estatísticas nas áreas das ciências biológicas e médicas. Belém: IDSM, 2007.

BÁRCENAS-REYES, I.; LOZA-RUBIO, E.; ZENDEJAS-MARTINEZ, H.; LUNA-SORIA, H.; CANTÓ-ALARCÓN, G.J; MILIÁN-SUAZO, F.. Comportamiento epidemiológico de la rabia paralítica bovina em la region central de México, 2001-2013. Revista Pan-Americana Salud Publica, v.38, n.5, p.396-402, 2015.

BLACKWOOD, J. C.; STRICTER, D. G.; ALTIZER, S.; ROHANI, P. Resolving the roles of immunity, pathogenesis, and immigration for rabies persistence in vampire bats. Proceeding of the National Academy of Sciences of the United States of America, v.110, n.51, p.20837-20837, 2013. DOI: https://doi.org/10.1073/pnas.1308817110

COELHO, A. S.; TOLEDO, P.M.; VIEIRA, I. C. G.; CANTO, O.; ADAMI, M.; GOMES, A. R.; NARVAES, I. S.. Impactos das 
mudanças de uso da terra nas áreas prioritárias para conservação da biodiversidade no nordeste do estado do Pará, Brasil. Boletim do Museu Paraense Emílio Goeldi. Ciências Naturais, v.13, n.1, p.107-120, 2018.

CORDEIRO, I. M. C. C.; ARBAGE, M. J. C.; SCHWARTZ, G.. Nordeste do Pará: configuração atual e aspectos identificários. In: CORDEIRO, I. M. C. C.;

RANGELVASCONCELOS, L. G. T.; SCHWARTZ, G.; OLIVEIRA, F. A.. Nordeste Paraense: panorama geral e uso sustentável das florestas secundárias. Belém: EDUFRA, 2017. p.19-58.

COSTA, L. J. C.. Composição da quiropterofauna e sua soroprevalência de anticorpos contra o vírus da raiva no Nordeste do Pará. Dissertação (Mestrado em Biologia Ambiental) - Universidade Federal do Pará, Belém, 2011.

DIOGO FILHO, A. A.; SANTOS, A. S.; SILVA, M. X.; OLIVEIRA, T. M.; COELHO, A. M.; PATEZ, D. C.. O uso da terra e a distribuição de casos de raiva bovina em Goiás, Brasil, 1985 a 2016. Multi-Science Journal, v.1, n.8, 2017. DOI: https://doi.org/10.33837/msj.v1i8.470

DOGNANI, R.; PIERRE, E. J.; SILVA, M. C. P.; PATRÍCIO, M. A. C.; COSTA, S. C.; PRADO, J. R.; LISBÔA, J. A. N.. Epidemiologia descritiva da raiva dos herbívoros notificados no estado do Paraná entre 1977 e 2012. Pesquisa Veterinária Brasileira, v.36, n.1, p.1145-1154, 2016. DOI: https://doi.org/10.1590/s0100-736×2016001200001

FERNANDES, M. E. B.; COSTA, L. J.; ANDRADE, F. A. G.; SILVA, L. P.. Rabies in humans and non-human in the state of Pará. Brazilian Journal Infectious Diseases, Salvador, v.17, n.2, p.251-253, 2013. DOI: https://doi.org/10.1016/j.bjid.2012.10.015

GOMES, A. B. B.; FERNANDES, L. L.. Estudo do regime pluviométrico da microrregião do Salgado no estado do Pará. Revista AIDIS de Ingeniería y Ciencias Ambientales: Investigación, Dessarollo y Práctica, v.12, n.2, p.295-312, 2019. DOI:

http://doi.org/10.22201/iingen.0718378xe.2019.12.2.62023

IBGE. Instituto Brasileiro de Geografia e Estatística. Divisão regional do Brasil: microrregiões geográficas. 2020a.

IBGE. Instituto Brasileiro de Geografia e Estatística. Censo demográfico: população: 2010, Nordeste Paraense. 2020b.

IBGE. Instituto Brasileiro de Geografia e Estatística. Pesquisa da Pecuária Municipal: Efetivo dos rebanhos, por tipo de rebanho: 2006 a 2018. 2020c.

INPE. Instituto Nacional de Pesquisas Espaciais.

Desmatamento nos municípios da Amazônia Legal. São José dos Campos: INPE, 2020.

IPEA. Instituto de Pesquisa Econômica Aplicada. Texto para discussão: Inserção no mercado internacional e a produção de carnes no Brasil. Rio de janeiro: IPEA, 2019.

MORAES, B. C.; COSTA, J. M. N.; COSTA, A. C. L.; COSTA, M. H.. Variação espacial e temporal da precipitação no Estado do Pará. Acta Amazônica, v.35, n.2, p.207-214, 2005. DOI: https://doi.org/10.1590/S0044-59672005000200010
NEVES, P. A. P. F. G.; SILVA, L. M.; PONTES, A. N.; PAULA, M. T.. Correlação entre pecuária e desmatamento em municípios da mesorregião sudeste do estado do Pará, Brasil. Ambiência: Revista do Setor de Ciências Agrárias e Ambientais, v.10, n.3, p.795-806, 2014. DOI: https://doi.org/10.5935/ambiencia.2014.03.11

PARÁ. Portaria N. 3.592 de $\mathbf{2 3}$ de outubro de 2018. Resolve instituir a obrigatoriedade de vacinação contra a raiva dos herbívoros, a partir de 3 meses de idade para bovinos, bubalinos, ovinos, caprinos e equídeos, nos municípios citados no anexo I. Belém: DOE.

PEREIRA, C.; SALLIS, E. S. V.; GRECCO, F. B.; RAFFI, M. B.; SOARES, M. P.; SCHILD, A. L.. Raiva em bovinos na Região Sul do Rio Grande do Sul: epidemiologia e diagnóstico imunohistoquímico. Pesquisa Veterinária Brasileira, v.31, n.4, 2011. DOI: http://dx.doi.org/10.1590/S0100736X2011000400010

PÓVOAS, D. R.; CHAVES, N. P.; BEZERRA, D. C.; ALMEIDA, V. M.; SARAIVA, L. Q.. Raiva em herbívoros no estado do Maranhão: um estudo retrospectivo. Revista Brasileira de Ciência Veterinária, v.19, n.2, p.86-89, 2012. DOI: http://dx.doi.org/10.4322/rbcv.2014.083

PUGA, L. C. H. P.. Modelagem espacial da ocorrência de mordeduras de morcegos hematófagos na Zona da Mata de Minas Gerais. Tese (Doutorado em ciência) - Universidade Federal de Viçosa, Viçosa, 2015.

QUEIROZ, L. H.; CARVALHO, C.; BUSO, D. S.; FERRARI, C. I. L.; PEDRO, W. A.. Perfil epidemiológico da raiva na região Noroeste do Estado de São Paulo no período de 1993 a 2007. Revista da Sociedade Brasileira de Medicina Tropical, v.42, n.1, p.9-14, 2009. DOI:

http://dx.doi.org/10.1590/S0037-86822009000100003

RIBEIRO, T. M. P.; TEIXEIRA, D. G.; REIS, T. S.; SANTOS, H. D.; MOURA, L. T. S.; BRASILEIRO, A. C. M.. Casos notificados de raiva em bovinos na região norte do Brasil no período de 2005 - 2017. Jornal Interdisciplinar de Biociências, v.33, n.1, p.42-46, 2018. DOI: https://doi.org/10.26694/jibi.v3i1.6666

RIVERO, S.; ALMEIDA, O.; ÁVILA, S.; OLIVEIRA, W.. Pecuária e desmatamento: uma análise das principais causas diretas do desmatamento na Amazônia. Nova Economia, v.19, n.1, p.41-66, 2009. DOI: https://doi.org/10.1590/S0103$\underline{63512009000100003}$

RODENBUSH, C. R.; FERREIRA, J. C.; ROSA, J. C. A.; MIGLIAVACCA, V. F.; PERES, M. E.; ALMEIDA, L. L.. Spatial and temporal description of laboratory diagnosis of bovine rabies in the State of Rio Grande do Sul, Brazil. Acta Scientiae Veterinariae, v.44, n.1, 2016. DOI: https://doi.org/10.22456/1679-9216.81212

RODRIGUES, É. D. L.; FREITAS, T. A.; PAIVA, F. A. S.; PEREIRA, A. S.; COELHO, T. F. S. B.; ROSA, E. S. T.; CASSEB, A. R.;

CASSEB, L. M. N.. Prevalência de raiva animal no estado do Pará, no período de 2004 a 2013. Revista Pan-Amazônica de Saúde, v.9, n.4, p.57-62, 2018. DOI: http://dx.doi.org/10.5123/S2176-62232018000400006

SILVA, G. C. P.; SANTOS, R. F.; ROCHA, S. M.; REIS, V. G. L.; SANTOS, G. R.; GODOY, H. P.; MATHIAS, L. A.; NOCITI, D. L. $P$.. Perfil da ocorrência de raiva animal em diferentes 
espécies no estado de Mato Grosso, Brasil, de 2002 a 2011. Revista Brasileira de Ciência Veterinária, v.24, n.3, p.151156, 2017. DOI: https://doi.org/10.4322/rbcv.2017.029

SILVA, J. A.; MOREIRA, E. C.; HADDAD, J. P. A.; MODENA, C. M.; TUBALDINI, M. A. S.. Distribuição temporal e espacial da raiva bovina em Minas Gerais, 1976 a 1997. Arquivo Brasileiro de Medicina Veterinária e Zootecnia, v.53, n.3, 2001. DOI: https://doi.org/10.1590/S0102$\underline{09352001000300001}$

SILVA, L. P.; PINTO, A. P. V. B.; PONTES, A. N.; BICHARA, C. N. C.. Epidemiologia da raiva em herbívoros domésticos em uma localidade na Amazônia brasileira. Revista Ibero Americana de Ciências Ambientais, v.11, n.3, p.105-112, 2020. DOI: http://doi.org/10.6008/CBPC21796858.2020.003.0010

SOUSA, F. D. N.. Epidemiologia e distribuição espacial da raiva em herbívoros no estado de Pernambuco, Brasil. Tese (Doutorado em Ciência Veterinária) - Universidade Federal Rural de Pernambuco, 2019.
SOUZA, P. G.; AMARAL, B. M. P. M.; GITTI, C. B.. Raiva animal na cidade do Rio de Janeiro: emergência da doença em morcegos e novos desafios para o controle. Revista Instituto Adolfo Lutz, v.73, n.1, p.119-124. 2014. DOI:

https://doi.org/10.18241/0073-98552014731596

TEIXEIRA, L. H. M.; TOMAZ, L. A. G.; LINHARES, G. F. C.; SANTOS, M. F. C.; JAYME, V. S.. Distribuição espaço-temporal dos diagnósticos laboratoriais da raiva animal. Ciência Animal Brasileira, v.16, n.1, p.144-157, 2015. DOI: http://dx.doi.org/10.1590/1809-6891v16i131282

VILLELA, R.; BUENO, R. S.. A expansão do desmatamento no estado do Pará: população, dinâmicas territoriais e escalas de análise. In: CONGRESSO DE LA ASSOCIACIÓN LATINOAMERICANA DE POBLACION, 7; ENCONTRO NACIONAL DE ESTUDOS POPULACIONAIS, 20. Anais. São Paulo: ABEP, 2016.

WHO. World Health Organization. WHO expert consultation on rabies: third report. Geneva: WHO Press, 2018.

A CBPC - Companhia Brasileira de Produção Científica (CNPJ: 11.221.422/0001-03) detém os direitos materiais desta publicação. Os direitos referem-se à publicação do trabalho em qualquer parte do mundo, incluindo os direitos às renovaç̃oses, expansões e disseminações da contribuiç̃o, bem como outros direitos subsidiários. Todos os trabalhos publicados eletronicamente poderão posteriormente ser publicados em coletâneas impressas sob coordenação da Sustenere Publishing, da Companhia Brasileira de Produção Científica e seus parceiros autorizados. Os (as) autores (as) preservam os direitos autorais, mas não têm permissão para a publicação da contribuição em outro meio, impresso ou digital, em português ou em tradução. 